\title{
HIV-1 drug resistance genotypic profiles in children with undetectable plasma viremia during antiretroviral therapy
}

\section{Authors}

Daniela Souza Araújo de Angelis $^{1}$

Adriana Fumie Tateno ${ }^{1}$ Ricardo Sobhie Diaz ${ }^{2}$

Regina Célia de Menezes Succi ${ }^{2}$

Claudio Sergio Pannuti ${ }^{1}$

Aida de Fátima Barbosa Gouvea $^{2}$

Daisy Maria Machado ${ }^{1,2}$

${ }^{1}$ Laboratório de Virologia, Instituto de Medicina Tropical de São Paulo, Universidade de São Paulo, São Paulo, Brazil

${ }^{2}$ Universidade Federal de São Paulo, São Paulo, Brazi

Submitted on: 3/5/2010 Approved on: 10/20/2010

Correspondence to: Daisy Maria Machado Av. Dr. Enéas de Carvalho Aguiar, 470 05403-000

São Paulo, Brazil Phone: 55(11)3061-7020 dm.machado@uol.com.br

Financial Support: This work was supported by the Brazilian research agencies FAPESP (grant number 01/11086-6) and CNPQ.

We declare no conflict of interest.

\begin{abstract}
Treatment of HIV-1 infection with highly active antiretroviral therapy has led to sustained viral suppression in the plasma in a large number of children. However, studies have suggested that the integrated provirus in resting CD4+ T lymphocytes could be a source of reactivatable virus and maintain drug-resistant virus. We evaluated the resistance-related mutations in children receiving antiretroviral therapy with prolonged viral suppression. Thirty-two peripheral blood mononuclear cell samples from 16 children with viral loads that had been below detection limits for at least 12 months were obtained at two different time points and the DNAs sequenced. The median CD4 cell count was 1,016 cells/ $\mathrm{mm}^{3}(347-2,588)$ and 938 cells $/ \mathrm{mm}^{3}(440-3,038)$ at the first and second time points, respectively. The median follow-up time was 15 months (9-27). Six (37.5\%) and seven (43.75\%) of the 16 patients showed at least one NRTI-associated mutation in the first and second samples, respectively. Two out of $16(12.5 \%)$ had an NNRTI-associated mutation at the first time point and three out of $16(18.75 \%)$ at the second. In addition, 14 out of $16(87.5 \%)$ had at least one PI-associated mutation at both time points. Despite plasma HIV-1 RNA suppression for at least 12 months, resistance-related mutations from previous antiretroviral failures could still be detected in archival virus. Furthermore, viral evolution occurred at the reverse transcriptase region in spite of viral suppression to levels below 400 copies/ $\mathrm{mL}$. Persistence of archival resistant virus may be relevant when considering future treatment options.
\end{abstract} Keywords: children; HIV-1; prolonged viral suppression; antiretroviral therapy; antiretroviral resistance.

[Braz J Infect Dis 2011;15(1):60-65] CElsevier Editora Ltda.

\section{INTRODUCTION}

Treatment of human immunodeficiency virus type 1 (HIV-1)-infected individuals with highly active antiretroviral therapy (HAART) has dramatically changed the course of the infection, reducing mortality and morbidity events associated with this disease. ${ }^{1-3}$ After HAART, a great number of patients had plasma viremia reduced to below the detection limits of current sensitive assays. ${ }^{4-6}$ Antiretroviral therapy (ART) in children has special features, and consequently, results obtained from clinical trials in adults may not be representative of the results obtained when using ART in children., Studies have shown that there is poor maintenance of viral load suppression in children, with up to half of those studied showing viral rebound within a year of treatment. ${ }^{9,10}$

In patients on HAART, HIV-1 persistence is evidenced by free virus in the plasma; given the short half-life of free virus, this residual viremia indicates active virus production. ${ }^{11}$ However, the virus is able to persist as a result of several potential mechanisms, such as its ability to establish a state of latent infection in resting memory CD4+ T cells. ${ }^{12,13}$ Sensitive assays have demonstrated that resting memory $\mathrm{CD} 4+\mathrm{T}$ cells retain replicationcompetent viral DNA that may be reactivated to produce virus even in patients with prolonged suppression of plasma viremia. ${ }^{14}$

Given the low fidelity of the HIV reverse transcriptase enzyme combined with the high replication rate of the virus, it is not surprising that even triple-class HAART therapy eventually fails in the vast majority of patients and is typically associated with the emergence of resistance to viral reverse-transcriptase (RT) and protease (PT) inhibitors, the currently used antiretroviral agents. ${ }^{15-17}$

To determine whether the integrated proviruses in resting CD4+ $\mathrm{T}$ cells are associated with the development of drug-resistance mutations, we studied a group of Brazilian children who had prolonged suppression of viral replication under ART. 


\section{METHODS}

\section{Patients and study design}

The study involved 32 samples of peripheral-blood mononuclear cells (PBMC) from 16 children followed up at the Pediatric Infectious Disease Clinic (CEADIPE) at the Universidade Federal de São Paulo, Brazil, (UNIFESP) at two different time points. The first sample was collected at inclusion, and the second after a minimum of nine months of follow-up. The inclusion criteria were (I) $\mathrm{VL}<400$ copies/mL with virological suppression ( $\mathrm{VL}<400$ copies $/ \mathrm{mL}$ ) maintained for at least 12 months at baseline and (II) treatment with ART and only one viral rebound with $>1,000$ copies $/ \mathrm{mL}$ during the 12 months prior to baseline. The parents or guardians of the children signed informed consent documents, and the study was approved by the institutional review board. The samples were collected from October 2002 to March 2005.

The children were monitored every three months, when they were examined physically and blood samples were collected for serial measurements of laboratory markers of HIV-1 infection, such as T-cell subsets and viral loads, and for safety tests. There was not a uniform approach to the antiretroviral treatment in the background regimen given. Instead, each pediatrician administered the appropriate ART regimen and changed the drugs according to his/her interpretation of the data and international guidelines. Each clinician measured adherence by interviews with parents or guardians.

\section{Amplification of HIV-1 pol from proviral DNA}

PCR amplification of purified proviral DNA was performed as previously described. ${ }^{18}$ The cycling conditions were as follows: 5 cycles of $1 \mathrm{~min}$ at $94^{\circ} \mathrm{C}, 1 \mathrm{~min}$ at $52^{\circ} \mathrm{C}$ and $1 \mathrm{~min}$ at $72^{\circ} \mathrm{C}$, followed by 25 cycles of $1 \mathrm{~min}$ at $94^{\circ} \mathrm{C}, 1 \mathrm{~min}$ at $55^{\circ} \mathrm{C}$ and $1 \mathrm{~min}$ at $72^{\circ} \mathrm{C}$. The product was purified, and RT and protease regions were sequenced.

\section{Genotypic analysis of HIV-1 isolates}

Genotypic HIV-1 drug resistance was determined using the Applied Biosystems ViroSeq HIV-1 Genotyping Kit. The HIV-1 protease and reverse transcriptase regions were analyzed using an $\mathrm{ABI} 377$ sequencer and associated Sequence Navigator software. Drug-resistance-associated mutations were defined according to the Stanford University HIV Drug Resistance Database (http://hivdb.stanford.edu) and antiretroviral resistance profile defined according to the Brazilian National AIDS guidelines for antiretroviral resistance interpretation (RENAGENO: http://www.aids.gov.br).

\section{RESULTS}

\section{Population characteristics}

The main characteristics of the study population at baseline are summarized in Table 1. The median follow-up time was 15 months (9-27). Fourteen patients $(87.5 \%)$ were on HAART at the time of the first sample, and two $(12.5 \%)$ were receiving two NRTIs. The median CD4+ T-cell count was 1,016 cells/ $\mathrm{mm}^{3}(347-2,588)$ and 938 cells $/ \mathrm{mm}^{3}(440-3,038)$ at the first and second time points, respectively. All children had HIV-1 RNA plasma levels below the detection limits on entry to the study (400 copies $/ \mathrm{mL}$ ). There were no differences in immune and clinical classifications for the two time points.

\section{Resistance-associated mutation profiles}

Thirty-two PBMC DNA samples were extracted from the 16 patients who had had HIV RNA levels $<400$ copies $/ \mathrm{mL}$

Table 1. Baseline characteristics of the study population

\begin{tabular}{|c|c|c|}
\hline & $\begin{array}{c}\text { Parameter } \\
\text { Age (years) } \\
\text { Male sex (\%) }\end{array}$ & $\begin{array}{c}\text { Patients }(\mathrm{n}=16) \\
11(6-15) \\
8(50 \%)\end{array}$ \\
\hline Therapy & First time point & Second time point \\
\hline $2 \mathrm{NRTI}+1 \mathrm{PI}$ & 10 & 9 \\
\hline $2 \mathrm{NRTI}+1 \mathrm{NNRT}$ & 2 & 4 \\
\hline $2 \mathrm{NRTI}+2$ PI & 1 & 1 \\
\hline $\begin{array}{l}2 \text { NRTI + } 2 \text { PI } \\
+1 \text { NNRTI }\end{array}$ & 1 & 1 \\
\hline 2 NRTI & 2 & 1 \\
\hline $\begin{array}{l}\text { Baseline CD4 } \\
\text { cell count } \\
\left(\text { cells } / \text { mm }^{3}\right)\end{array}$ & $1,016(347-2,588)$ & $938(440-3,038)$ \\
\hline \multicolumn{3}{|l|}{$\begin{array}{l}\mathrm{CDC}^{\mathrm{b}} \text { clinical } \\
\text { classification }\end{array}$} \\
\hline $\mathrm{N}$ & 1 & 1 \\
\hline $\mathrm{A}$ & 3 & 3 \\
\hline B & 6 & 6 \\
\hline $\mathrm{C}$ & 6 & 6 \\
\hline \multicolumn{3}{|l|}{$\begin{array}{l}\text { Immune } \\
\text { classification }\end{array}$} \\
\hline 1 & 4 & 4 \\
\hline 2 & 6 & 6 \\
\hline 3 & 6 & 6 \\
\hline
\end{tabular}

aMedian (range); ${ }^{\mathrm{b} C e n t e r s ~ f o r ~ D i s e a s e ~ C o n t r o l ~ a n d ~ P r e v e n t i o n ~}$ Classification. 
for at least 12 months after they started ART. Thirteen patients maintained suppression of viral replication throughout the study. Genotypic drug resistance of all samples was determined by amplification and HIV-1 sequencing.

Fifteen out of the 16 individuals $(93.75 \%)$ had at least one mutation related to decreased susceptibility to antiretroviral therapy. The percentage of patients with mutations related to drug resistance varied according to the drug classes used, with $31.25 \%, 12.5 \%$ and $31.25 \%$ having NRTI, NNRTI and PI-related mutations, respectively, at the first time point, and $37.5 \%, 18.75 \%$ and $31.25 \%$ having NRTI, NNRTI and PI-related mutations, respectively, at the second time point. Figures 1 and 2 show all the mutations found for both time points for each reverse-transcriptase and protease region.

Two out of the 16 children (12.5\%) were resistant to all three drug classes whereas 9/16 (56.25\%) did not have any resistance-associated genotypic mutations at the first time point. At the second time point, 3/16 (18.75\%) were resistant to all three drug classes.

According to the genotype analysis, three out of the 16 children $(18.75 \%)$ were resistant to ZDV, and 2/16 (12.5\%) had intermediate resistance to this drug; $1 / 16(6.3 \%)$ and $2 / 16$ $(12.5 \%)$ were resistant or had intermediate resistance, respectively, to ddI; $2 / 16(12.5 \%)$ were resistant to $3 \mathrm{TC}$ and $\mathrm{ABC}$; and $3 / 16(18.75 \%)$ were resistant to $\mathrm{d} 4 \mathrm{~T}$. A small percentage of children were found to have mutations conferring resistance to nevirapine (12.5\%) and efavirenz (6.3\%) at the first time point.

At the second time point, four out of the 16 children (25\%) were resistant to ZDV whereas $2 / 16$ had intermediate resistance to this drug (12.5\%); $1 / 16(6.3 \%)$ and $3 / 16$ $(18.75 \%)$ were resistant or had intermediate resistance, respectively, to ddI; $3 / 16(18.75 \%)$ were resistant to $3 \mathrm{TC}$ and ABC; and 4/16 (25\%) were resistant to d4T. Three out of $16(18.75 \%)$ were found to have mutations conferring resistance to nevirapine.

Figure 1: Mutations found in the reverse transcriptase region at both time points.

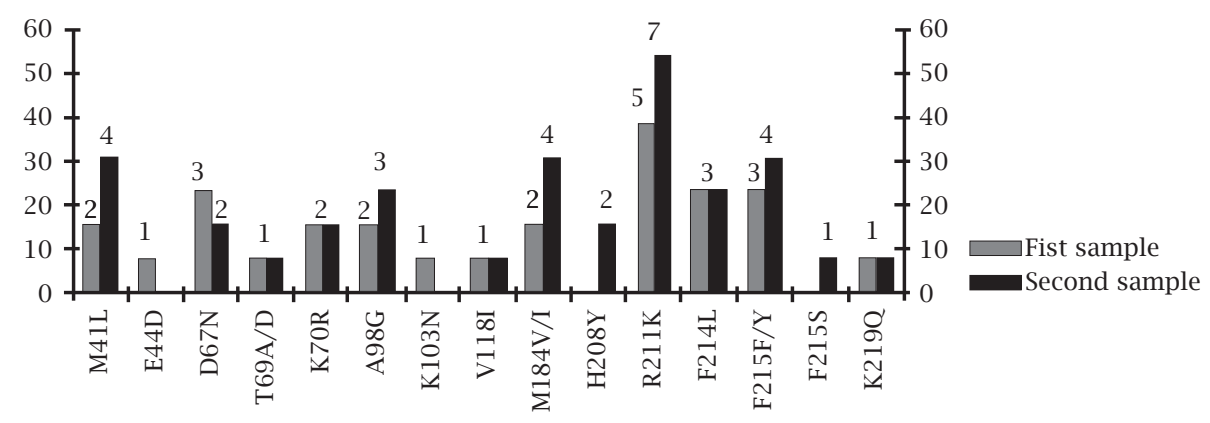

Figure 2: Mutations found in the protease region at both time points.

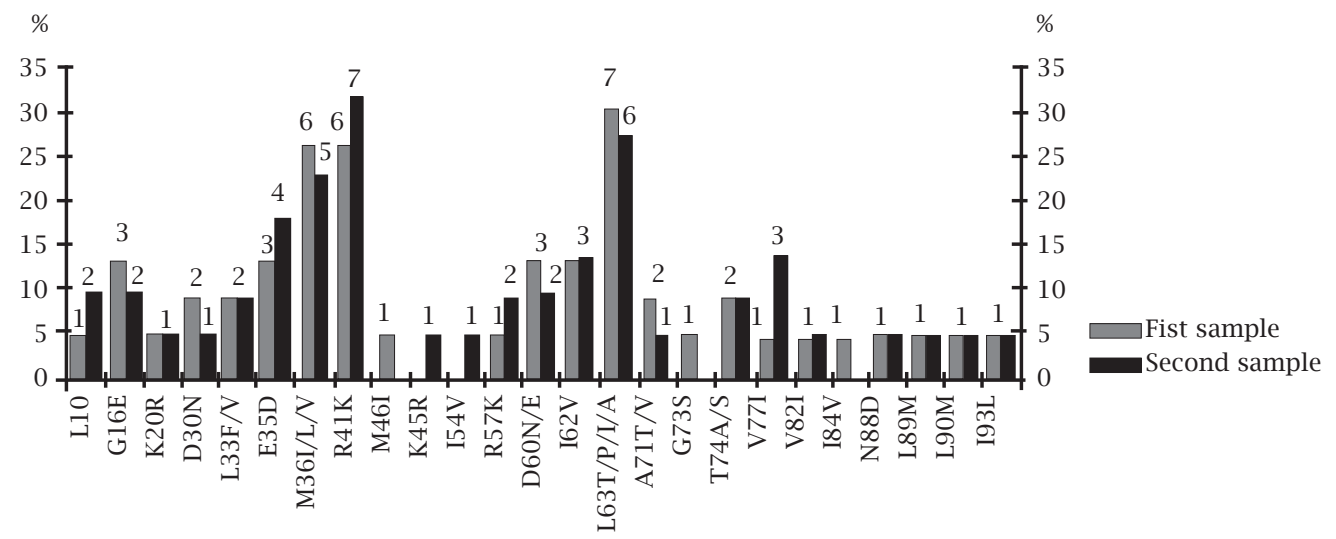


Table 2 shows the mutations associated with decreased susceptibility to each antiretroviral class and the antiretroviral-therapy history for each patient. The major mutations related to PI resistance in the first sample were D30N $(\mathrm{n}=2)$, M46I $(\mathrm{n}=1)$, V82I $(\mathrm{n}=1), \mathrm{I} 84 \mathrm{~V}(\mathrm{n}=1)$ and L90M $(n=1)$, corresponding to the following rates of total resistance and intermediate resistance to the different drugs, respectively: RTV (12.5\%; 6.3\%); APV (6.3\%; 0\%);
SQV (12.5\%; 12.5\%), IDV (6.3\%; 12.5\%), NFV (18.8\%; $6.3 \%)$, LPV/RTV $(0 \%$; $0 \%)$. The corresponding figures for the second sample were: D30N $(\mathrm{n}=1)$, M46I $(\mathrm{n}=0)$, V82I $(\mathrm{n}=1)$, I84V $(\mathrm{n}=0)$ and L90M $(\mathrm{n}=1)$, corresponding to the following rates of total resistance and intermediate resistance to the different drugs, respectively: RTV (6.3\%; $0 \%)$; APV (6.3\%; 0\%), SQV (6.3\%; 12.5\%); IDV (6.3\%; $6.3 \%)$, NFV (12.5\%; 6.3\%), LPV/RTV (0\%; 0\%).

Table 2. Genotypic profiles of viral isolates and antiretroviral exposure for each patient at both time points

\begin{tabular}{|c|c|c|c|c|}
\hline ID & ITRN & ITRNN & IP & TARV* \\
\hline 01-1 & V118DV & None & G16E; L24*; V32G; I47R & ZDV; NVP; ddI; d4T; NFV \\
\hline 01-2 & None & None & G16E & ZDV; NVP; ddI; d4T; NFV \\
\hline $02-1$ & R211G & None & K20R; R41K; A71V; I93L & ZDV; 3TC; ddI; RTV \\
\hline $02-2$ & M184V; R211G & None & K20R; R41K; A71V; I93L & ZDV; 3TC; ddI; RTV \\
\hline 03-1 & E44K; D67N; R211K & G190K & $\begin{array}{l}\text { G16E; D30N; E34K; E35N; M36I; } \\
\text { R41K; M46I; G48E; D60N; I62V }\end{array}$ & ZDV; 3TC; $d 4 T ; R T V$ \\
\hline 03-2 & $\begin{array}{l}\text { M41L; M184V; } \\
\text { R211K; T215Y }\end{array}$ & None & G16E; E35D; M36I; R41K; K45R; I62V & ZDV; 3TC; $d 4 T ; R T V$ \\
\hline 04-1 & $\mathrm{R} 211 \mathrm{~K}$ & None & E35D; M36I; R41K; L63S & ddI; NFV; $d 4 T ; 3 T C ; E F V$ \\
\hline 04-2 & $\mathrm{R} 211 \mathrm{~K}$ & None & E35D; M36I; R41K; L63S & ddI; NFV; $d 4 T ; 3 T C ; E F V$ \\
\hline 05-1 & $\begin{array}{l}\text { M41L; V118IV; M184V; } \\
\text { F214L; T215F }\end{array}$ & $\begin{array}{l}\text { A98G; L100LV; } \\
\text { K103N; V106I }\end{array}$ & $\begin{array}{l}\text { D30N; L33F; M36L; R57K; } \\
\text { D60E; L63P; A71V; N88D }\end{array}$ & 3TC; d4T; NFV; ddI; ZDV; EFV \\
\hline $05-2$ & $\begin{array}{l}\text { M41L; K70KQ; V118I; M184V; } \\
\text { H208Y; F214L; T215F }\end{array}$ & $\begin{array}{l}\text { A98G; } \\
\text { V106I }\end{array}$ & $\begin{array}{l}\text { D30N; L33F; M36L; R41KR; } \\
\text { R57K; D60E; L63P }\end{array}$ & 3TC; d4T; NFV; ddI; ZDV ; EFV \\
\hline 06-1 & None & None & None & ZDV; RTV; EFV; 3TC; d4T; NFV \\
\hline $06-2$ & R211KR & G190GR & None & ZDV; RTV; $E F V ; 3 T C ; \mathrm{d} 4 \mathrm{~T} ; \mathrm{NFV}$ \\
\hline $07-1$ & $\mathrm{R} 211 \mathrm{X}$ & None & V77I; V82I & ZDV; EFV; NVP; $d d I ; d 4 T ; R T V$ \\
\hline $07-2$ & $\mathrm{R} 211 \mathrm{~K}$ & None & R57K; V77I; V82I & ZDV; EFV; NVP; $d d I ; d 4 T ; R T V$ \\
\hline 08-1 & E44DE; F214L & None & L63I & ZDV; ddI; EFV; $d 4 T ; 3 T C ; N F V$ \\
\hline $08-2$ & F214L & M230IM & L63S; V77I & ZDV; ddI; EFV; $d 4 T ; 3 T C ; N F V$ \\
\hline 09-1 & V118D & None & L63A; T74AT & ZDV; ddI; $d 4 T ; 3 T C ; N F V$ \\
\hline 09-2 & M41L; T215S & A98G & L10I; L63A; T74AT; V77I & ZDV; ddI; $d 4 T ; 3 T C ; N F V$ \\
\hline $10-1$ & None & None & E35D; I47M; G48R; L63P & ZDV; ddI; EFV; d4T; 3TC \\
\hline $10-2$ & V118D & None & E35D; L63P & ZDV; ddI; d4T; 3TC; EFV; NVP \\
\hline 11-1 & None & None & M36I & ZDV; ddI \\
\hline $11-2$ & None & None & L63H & ZDV; ddI \\
\hline $12-1$ & $\mathrm{R} 211 \mathrm{~K}$ & None & G16E; L33V; E34K; G73S; L89M & ZDV; ddI; 3TC; d4T; RTV \\
\hline $12-2$ & $\mathrm{R} 211 \mathrm{~K}$ & None & L33V; L89M & ZDV; ddI; 3TC; d4T; RTV \\
\hline 13-1 & M41L; M184V; T215Y & None & R41K; D60E; I62V; L63P & ZDV; EFV; 3TC; d4T; RTV \\
\hline $13-2$ & M41L; M184V; T215Y & None & R41K; D60E; I62V; L63P & ZDV; EFV; 3TC; d4T; RTV \\
\hline 14-1 & $\begin{array}{l}\text { D67N; T69D; } \\
\text { K70R; R211K; }\end{array}$ & A98G & $\begin{array}{l}\text { L10I; E35D; M36V; R41K; } \\
\text { I62V; L63P; T74S; I84V; L90M }\end{array}$ & $\begin{array}{c}\text { ZDV; 3TC; NFV; RTV; ddI; d4T; } \\
\text { EFV; LPV/r }\end{array}$ \\
\hline $14-2$ & $\begin{array}{l}\text { D67N; T69D; K70R; H208Y; } \\
\text { R211K; F214L; T215F; K219Q }\end{array}$ & A98G & $\begin{array}{l}\text { L10I; E35D; M36V; R41K; } \\
\text { I54V; I62V; L63P; T74S; L90M }\end{array}$ & $\begin{array}{c}\text { ZDV; 3TC; NFV; RTV; ddI; } \\
\text { d4T; EFV; LPV/r }\end{array}$ \\
\hline 15-1 & D67N; K70R; R211K & None & M36I; L63S & ZDV; 3TC; RTV \\
\hline $15-2$ & D67N; K70R; R211K & None & M36I; L63S; & ZDV; 3TC; RTV \\
\hline $16-1$ & None & None & $\begin{array}{l}\text { R41K; L63P; L90V } \\
\text { 3TC; ABC; LPV/r }\end{array}$ & ZDV; RTV; d4T; ddI; NFV; EFV; \\
\hline $16-2$ & None & None & $\begin{array}{l}\text { R41K; L63P; N88D } \\
\text { 3TC; ABC; LPV/r }\end{array}$ & ZDV; RTV; d4T; ddI; NFV; EFV; \\
\hline
\end{tabular}

* Drug abbreviations: ZDV, zidovudine; 3TC, lamivudine; ddI, didanosine; d4T, stavudine; NVP, nevirapine; EFV, efavirenz; RTV, ritonavir; NFV, nelfinavir.; LPV, lopinavir; ABC, abacavir. The patients' regimens at the time the study was carried out including the drugs listed in boldface, italic type. 


\section{DISCUSSION}

Although HIV-RNA viral loads reach undetectable levels less frequently in HIV-infected children than they do in adults, ${ }^{19,20}$ we describe a selected group of children on ART who experienced long-term viral suppression. Several findings in the present study confirm that resistance can develop when the viremia level is below 400 copies $/ \mathrm{mL}$.

When Cohen Stuart et al. ${ }^{21}$ evaluated plasma samples with an average viral load of 76 copies $/ \mathrm{mL}$, they found that $72.7 \%$ of the viruses had resistance mutations to one or more drugs. However, when De la Rosa et al. ${ }^{1}$ studied adults' PBMC with viremia levels $<50$ copies $/ \mathrm{mL}$, they found that only $40 \%$ of viruses had one or more mutations related to resistance.

Our analysis showed a high frequency of viruses (94\%) with resistance-related mutations at both time points, with percentages varying according to the drug class. At the time the first samples were collected, there was a significantly higher percentage of viruses with mutations selected by NRTIs and PIs (31.3\%) than of viruses with mutations selected by NNRTIs (12.5\%). At the time the second samples were collected, $37.5 \%$ and $31.3 \%$ of the viruses were observed to have mutations selected by NRTIs and PIs, respectively, while the corresponding figure for NNRTIs was $18.8 \%$.

Naeger LK and Struble $\mathrm{KA}^{22}$ showed that lopinavir/ritonavir response rates were less than $30 \%$ when protease substitutions at M46, I54 or I84 were present at baseline. Two patients (ID 03 and 14) in the present study continued to have undetectable viral loads even in the presence of these mutations. However, the majority of sequences obtained from the latent reservoir showed a virus with mutations conferring resistance to drugs that were part of failed prior regimens. A striking result was the fact that this "archival" drug-resistant virus persisted despite continued treatment with the relevant drug with no viral replication.

In one patient (ID 14) who had previously been exposed to several therapeutic regimens containing ZDV, 3TC, NFV and RTV, the viral load first reached undetectable levels in October 2001 while the patient was undergoing the eighth therapeutic regimen, which contained d4T, ddI, EFV and LPV/r. Although the genotypic profile showed mutations associated with resistance to the three classes of drugs and sensitivity only to $\mathrm{LPV} / \mathrm{r}$, this patient continued to have complete viral suppression $(<400$ copies $/ \mathrm{mL})$ at the time the study was completed. The probable explanation for this is related to a reduction in viral fitness due to mutations. ${ }^{23} \mathrm{~A}$ similar finding was described by Ghosn et al..$^{24}$ in two patients with a virus that was resistant to at least two of the three drug classes in use, one of whom maintained complete viral suppression for 24 months and the other for 48 months.

Another critical issue relates to two children who used the first antiretroviral therapy (ID 11 and 15). Although maintaining undetectable viral loads, one of them had mu- tations selected by a nucleoside analogue and had the same profile in the two samples, while the other showed no relevant changes.

It is important to emphasize that three out of the six children who showed non-nucleoside related mutations (IDs 05,06 and 14) were receiving HAART containing this class of drug. With regard to the other three, one of them (ID 08) had been exposed to EFV in a prior regimen, and the other two (IDs 03 and 09) had never been exposed to an NNRTI before.

To summarize, we observed that $62.5 \%$ of the patients $(10 / 16)$ had no relevant changes in the genotypic profile at the RT region. In $83.3 \%$ (5/6), new substitutions could be found at the second time point. These were all related to resistance (codons 41, 98, 184, 208 and 215), suggesting viral evolution. Some mutations found at the first time point were not present at the second time point (codons 44, 67 and 103). In the PR region, we observed that $37.5 \%$ of the patients $(6 / 16)$ had no relevant changes in the genotypic profile. In $30 \%(3 / 10)$, new substitutions could be found in the second sample, all related to polymorphisms. The D30N mutation found in the first sample (ID 03) was not present in the second sample.

Despite our success in controlling viral replication, several children had mutant strains present in the lymphocytes, although this did not reflect any clinical or immunological deterioration. However, the persistence of the archival resistant virus may be relevant when considering future treatment options.

\section{ACKNOWLEDGEMENTS}

We thank the medical staff and nurses from CEADIPe and the laboratory staff from Instituto de Medicina Tropical de São Paulo for their contributions to this work.

This work was partially supported by: Fundação de Amparo à Pesquisa do Estado de São Paulo (FAPESP) - grant \# 01/11086-6 and Conselho Nacional de Desenvolvimento Científico e Tecnológico (CNPQ).

\section{REFERENCES}

1. de la Rosa R, Ruiz-Mateos E, Rubio A et al. Long-term virological outcome and resistance mutations at virological rebound in HIV-infected adults on protease inhibitor-sparing highly active antiretroviral therapy. J Antimicrob Chemother. 2004; 53(1):95-101.

2 Palella FJ Jr, Delaney KM, Moorman AC et al. Declining morbidity and mortality among patients with advanced human immunodeficiency virus infection. HIV Outpatient Study Investigators. N Engl J Med. 1998; 338(13):853-60.

3. Saitoh A, Hsia K, Fenton T et al. Persistence of human immunodeficiency virus (HIV) type 1 DNA in peripheral blood despite prolonged suppression of plasma HIV-1 RNA in children. J Infect Dis. 2002; 185(10):1409-16. 
4. Hermankova M, Ray SC, Ruff C et al. HIV-1 drug resistance profiles in children and adults with viral load of $<50$ copies $/ \mathrm{mL}$ receiving combination therapy. JAMA 2001; 286(2):196-207.

5. Izopet J, Sailler L, Sandres K et al. Intermittent selection pressure with zidovudine plus zalcitabine treatment reduces the emergence in vivo of zidovudine resistance HIV mutations. J Med Virol. 1999; 57(2):163-8.

6. Persaud D, Pierson T, Ruff C et al. A stable latent reservoir for HIV-1 in resting CD4(+) T lymphocytes in infected children. J Clin Invest. 2000; 105(7):995-1003.

7. Resino S, Larru B, Maria Bellon J et al. Effects of highly active antiretroviral therapy with nelfinavir in vertically HIV-1 infected children: 3 years of follow-up. Long-term response to nelfinavir in children. BMC Infect Dis. 2006; 6:107.

8. De Rossi A. Virological and immunological response to antiretroviral therapy in HIV-1 infected children: genotypic and phenotypic assays in monitoring virological failure. New Microbiol. 2004; 27(2 Suppl1):45-50.

9. Hermione Lyall EG. Paediatric HIV in 2002--a treatable and preventable infection. J Clin Virol. 2002; 25(2):107-19.

10. Gavin PJ, Yogev R. The role of protease inhibitor therapy in children with HIV infection. Paediatr Drugs 2002; 4(9):581-607.

11. Bailey JR, Sedaghat AR, Kieffer T et al. Residual Human Immunodeficiency Virus Type 1 Viremia in Some Patients on Antiretroviral Therapy Is Dominated by a Small Number of Invariant Clones Rarely Found in Circulating CD4 T Cells. J Virol. 2006; 80(13):6441-57.

12. Ruff CT, Ray SC, Kwon P et al. Persistence of wild-type virus and lack of temporal structure in the latent reservoir for human immunodeficiency virus type 1 in pediatric patients with extensive antiretroviral exposure. J Virol. 2002; 76(18):9481-92.

13. Lambotte O, Chaix ML, Gubler B et al. The lymphocyte HIV reservoir in patients on long-term HAART is a memory of virus evolution. AIDS 2004; 18(8):1147-58.

14. Zanchetta M, Walker S, Burighel $\mathrm{N}$ et al. Long-term decay of the HIV-1 reservoir in HIV-1-infected children treated with Highly Active Antiretroviral Therapy. J Infect Dis. 2006; 193:1718-26.
15. Matthews T, Salgo M, Greenberg M et al. Enfuvirtide: the first therapy to inhibit the entry of HIV-1 into host CD4 lymphocytes. Nat Rev Drug Discov. 2004; 3(3):215-25.

16. Iglesias-Ussel MD, Casado C, Yuste E, Olivares I, LopezGalindez C. In vitro analysis of human immunodeficiency virus type 1 resistance to nevirapine and fitness determination of resistant variants. J Gen Virol. 2002; 83(Pt 1):93101.

17. Sturmer M, Berger A, Preiser W. HIV-1 genotyping: comparison of two commercially available assays. Expert Rev Mol Diagn. 2004; 4(3):281-91.

18. Zhang L, Ramratnam B, Tenner-Racz Ket al. Quantifying residual HIV-1 replication in patients receiving combination anti-retroviral therapy. N Engl J Med. 1999; 340(21):160513.

19. Starr SE, Fletcher CV, Spector AS et al. Combination therapy with efavirenz, nelfinavir, and nucleoside reverse-transcriptase inhibitors in children infected with human immunodeficiency vírus type 1 . Pediatric AIDS Clinical Trials Group 382 Team. N Engl J Med.1999; 341(25):1874-81.

20. Van Rossum AM, Fraaij PL, de Groot R. Efficacy of highly active anti-retroviral therapy in HIV-1 infected children. Lancet Infect Dis. 2002; 2(2):93-102.

21. Cohen Stuart JW, Wensing AM, Kovacs C et al. Transient relapses ("blips") of plasma HIV RNA levels during HAART are associated with drug resistance. J Acquir Immune Defic Syndr. 2001; 28(2):105-13.

22. Naeger LK, Struble KA. Effect of baseline protease genotype and phenotype on HIV response to atazanavir/ritonavir in treatment-experienced patients. AIDS 2006; 20(6):847-53.

23. Lucas GM. Anti-retroviral adherence, drug resistance, viral fitness and HIV disease progression: a tangled web is woven. J Antimicrob Chemother. 2005; 55(4):413-6.

24. Ghosn J, Pellegrin I, Goujard C et al. HIV-1 resistant strains acquired at the time of primary infection massively fuel the cellular reservoir and persist for lengthy periods of time. AIDS 2006; 20(2):159-70. 